\title{
Nosocomial Legionnaires' Disease: Risque and Prevention
}

\author{
Jalila Tai $^{1,2}$, Mohamed Nabil Benchekroun ${ }^{2}$, Mly Mustapha Ennaji ${ }^{2}$, Mariam Mekkour ${ }^{1}$, Nozha Cohen ${ }^{1, *}$ \\ ${ }^{1}$ Division de Microbiologie et d'hygiène des Produits de l'Environnement, Institut Pasteur du Maroc, Casablanca, 20360, \\ Maroc \\ ${ }^{2}$ Laboratoire de Biotechnologie, de l'Environnement et de la Santé, Faculté des Sciences et Techniques, Université Hassan \\ II-Mohammedia, 146, Maroc
}

\begin{abstract}
In 1977, Fraser et al. described an outbreak of pneumonia among legionnaires attending a convention at a hotel in Philadelphia in 1976. Legionnaires' disease (LD) can be nosocomial, community acquired or travel related. The incidence of hospital-acquired legionellosis appears to be increasing. Colonization of water systems by Legionella spp. is ubiquitous in hospitals throughout the world. The outbreak, which later became known as legionnaires' disease, was caused by a new pleomorphic, faintly staining gram-negative bacillus, L. pneumophila, which was isolated at the Center for Disease Control from lung tissues of legionnaires who died. Risk assessment for this disease forms the basis for the institution of control measures. Detection and quantification of Legionella spp. in the environment, in particular in the hospital water distribution system is one of the cornerstones of risk assessment. This review summarizes the current state-of-the-art regarding these aspects and points out important areas which require further study. The environmental surveillance revealed that the centralized hot water distribution system of the hospital was colonized with Legionella. Methods of prevention of the organisms for eradication involved in hospital water systems.
\end{abstract}

Keywords Legionnaires' Disease, Nosocomial, Legionella Pneumophila, Environment, Risk Assessment, Prevention

\section{Introduction}

Hospital-acquired pneumonia (HAP) is considered the second most frequent cause of nosocomial infection, accounting for 15 to $20 \%$ of these infections[1]. Nosocomial Legionnaires' disease has become increasingly common, contributing up to 30 percent of hospital-acquired pnemonias in some institutions[2]. Legionnaires' disease, the pneumonic form of legionellosis, usually is acquired by inhalation or aspiration of legionellae from contaminated environmental sources. Potable water is an important source of both nosocomial and community acquired Legionella infections[3]. Nosocomial Legionnaires' disease is an important problem in some hospitals in the world. It has been estimated that $20-30 \%$ of legionellosis are nosocomial infections and that they are associated with a contamination of the hospital's water distribution system[4]. Colonization of hospital water distribution systems with $L$. pneumophila serogroup 1 has been repeatedly linked to acquisition of nosocomial Legionnaires' disease[5].

Obviously, the hospital/facility-related outbreaks do not have a seasonal distribution as with community acquired Legionnaire's disease[6]. Legionella is an opportunistic pathogen with widespread distribution in the environment.

* Corresponding author:

nozha.cohen@pasteur.ma (Nozha Cohen)

Published online at http://journal.sapub.org/fs

Copyright (C) 2012 Scientific \& Academic Publishing. All Rights Reserved
Numerous reports have demonstrated that the major sources for Legionnaires' disease are the potable water systems of large buildings including hospitals, nursing homes, and hotels. Legionella is a common cause of hospital acquired pneumonia, especially for immunocompromised patients[7]. An epidemiological investigation should be initiated in the event of microbiologically confirmed Legionella pneumonia in a patient, who was admitted to the hospital 2-10 days before the onset of illness, or if two or more patients are infected attending an outpatient clinic. Legionellosis of human intervention of the environment is the cause of emerged, since Legionella species are found in aquatic environments, and thrive in warm water and warm, damp places, such as cooling towers.

\section{History of Hospital-acquired legionnaires' Disease}

The earliest recognized community outbreak, diagnosed retrospectively, was in Austin, Minnesota in 1957[8] and the first reported outbreak of hospital acquired Legionnaires' disease was in a psychiatric hospital at St Elizabeth's in Washington DC in 1965[9]. The hospital housed 6000 patients in multiple buildings on a 350 acre $\left(1.4 \mathrm{~km}^{2}\right)$ campus, in which 81 patients contracted pneumonia, with 15 deaths. However, analysis of stored serum specimens in 1977 showed that 19 of 26 patients tested seroconverted to $L$. pneumophila serogroup 1. In July 1968, 144 visitors or personnel of a county health department in Pontiac, Michig 
an contracted an acute febrile myalgia[10]. The responsible agent was retrospectively determined to be Legionella, and the name given to this self-limited version of disease was "Pontiac Fever". Subsequent Legionnaires' disease epidemi cs have rarely implicated soil excavation, although disruptions of potable water systems and contamination of building plumbing systems during construction have been alternative explanations[11]. An interesting historical note is that the attempted assassin of US President Ronald Reagan is currently confined to this institution[12]. The largest outbreak of hospital acquired Legionnaires' disease occurred at the Wadsworth Veterans' Administration Medical Center (VAMC) in Los Angeles, with at least 218 confirmed cases from 1977 to 1982[13]. Since then, more than 300 reports of hospital-acquired Legionnaires' disease have appeared in peer-reviewed literature and public-health reports[13]. An outbreak of a pneumonia-type human disease in 1976 was found to have originated from a hotel cooling tower at the American Legion Convention in Philadelphia. Thus, the name was established as the Legionnaires' disease[14]. The cause of this outbreak was identified by the Centers for Disease Control (CDC), Atlanta, as bacteria. L. pneumophila has been recognized as an important cause of community and nosocomial pneumonia. Legionnaires' disease is known to cause hospital acquired pneumonia and may occur as part of an outbreak or sporadically $[15,16]$. Outbreaks are worldwi de and have been reported from India[17], Turkey[18], Italy[19] Taiwan[20, 21] and Poland[22]. These outbreaks are usually due to aspiration of contaminated drinking water, but an oxygen humidifier[23] and a decorative fountain were implicated in two reports. Eight cases occurred in a hospital that had installed a decorative water fountain in the lobby[24]. Two cases of Legionnaires' disease were diagnosed in stem cell transplant patients linked to exposure to a decorative water fountain in a radiation oncology suite[25]. In a French hospital, a case of Legionnaires' disease in a leukemia patient was linked to water from a washbasin in a hematology unit[26].

\section{Microbiology, Morphology, and Ecology}

\subsection{Taxonomy}

Legionellosis, the technical name for Legionnaires' disease, is caused by bacteria known as Legionella. Bacteria of the family Legionellaceae can be found in both natural and man-made environments[27]. Some investigators have proposed placing the legionellae in three separate genera: Legionella, Fluoribacter, and Tatlockia[28, 29]. However, recent studies using $16 \mathrm{~S}$ rRNA analysis confirm the family Legionellaceae as a single monophyletic subgroup within the gamma-2 subdivision of the Proteobacteria[30, 31]. The number of recognized species and serogroups of the genus Legionella continues to increase (Table 1). There are currently, the Legionella genus includes 52 species[32, 33] and more than 70 different serogroups, and more than 20 species have been proven to be causative agents of Legionnaires' disease on the basis of their isolation from clinical material[34, 14]. The species L. pneumophila accounts for approximately $90 \%$ of confirmed cases of legionellosis, and L. pneumophila serogroup 1 has been recognized as the most important agent in this regard, as that specific strain was initially implicated as the pathogen causative of Legionnaires' disease in 1977[34].

\subsection{Morphology}

Legionellae of all types have been isolated from natural environments in different areas of the world[27]. All Legionella species appear as Gram-negative coccobacilli[14 ]. They are unencapsulated, non spore forming, with physical dimensions from 0.3 to $0.9 \mu \mathrm{m}$ in width and from 2 to $20 \mu \mathrm{m}$ in length[14]. Most exhibit motility through one or more polar or lateral flagella[35]. These bacteria are aerobic, microaerophillic, and have a respirative metabolism that is non-fermentative and is based on the catabolism of amino acids for energy and carbon sources[36].

\subsection{Ecology}

Legionella can survive in varied water conditions, in temperatures of $0-68^{\circ} \mathrm{C}$, a $\mathrm{pH}$ range of 5.0-8.5[14], and a dissolved oxygen concentration in water of $0.2-15 \mathrm{ppm}[37]$. With the exception of natural hot springs where temperature ranges from $35^{\circ} \mathrm{C}$ to $40^{\circ} \mathrm{C}$, the sources of legionellosis are exclusively man-made water systems[38]. In water, a temperature range between $20^{\circ} \mathrm{C}$ to $45^{\circ} \mathrm{C}$ favors the growth of L. pneumophila[38]. At lower temperatures, Legionella appears to enter into a dormant stage until exposed to more favorable conditions[38]. It is found in freshwater ecosystems at low concentration, but from its natural habitat, the bacterium can colonize man made water systems where conditions are ideal for its massive growth and spreading, representing a public health problem[3]. The organisms classified in this genus are bacteria that are considered intracellular parasites. Legionellae multiplies within host cells, such as protozoa and the human macrophage[3, 39]. It's have been reported to multiply in 13 species of amoebae including Acanthamoeba, Hartmannella, Echinamoeba, Tetrahymena and Vahlkmpfia[40] and two species of ciliated protozoa[41]. The biofilm layer, commonly associated with water-distribution systems, is considered an important niche for Legionella, which can survive within it. It has been hypothesized that the biofilm, in which amoebae are present, may support the survival and multiplication of legionellae, and may be even outside a host cell[3]. Biofilms may provide the necessary supply of amino acids and organic carbon that are essential to its growth[42]. In the environment, Legionella is also found in association within free living protozoa that it has the ability to invade and in which it can multiply[38]. The reason why Legionella grow inside these amoebae is because the bacteria multiply intracellularly, and therefore require the amoebae to aid in reproduction. It has 
been determined that one amoebae can house enough Legionella bacteria to infect a human being, and this single amoebae is small enough to fit in one droplet of aerosolised water. A study evaluating factors associated with colonization of hospital water supply systems by Legionella spp. showed a statistically significant association between the presence of amoebae in potable water and Legionella colonization[43]. However, there was no correlation between concentrations of Legionella and the presence of amoebae[40].

\section{Assessment of the Clinical Impact}

The investigation of sources of sporadic cases of hospital-acquired Legionnaires' disease is often unrewarding, partly because of the ubiquitous nature of the organism. Risk assessment combined with environmental monitoring has been effective in predicting risk in studies in the USA, Italy, France, Taiwan, Spain and Greece[19, 44, 45], and most European countries now mandate routine culturing of the hospital drinking water for Legionella. Often, hospital water systems are colonized by Legionella and this contamination is responsible for most cases of hospital-acquired legionellosis. If a case of nosocomial Legionnaires' disease is detected, it is likely that additional cases will be discovered. Contamination of hospital hot water systems with $L$. pneumophila is of concern if this results in clinical illness. Some hospitals may not be aware of the occurrence of nosocomial Legionnaires' disease on their wards because of the difficulty in making the diagnosis when a routine diagnostic approach to nosocomial pneumonia is used. Approximately a quarter of all reported Legionnaires' disease cases in world acquire their infection inside a hospital. Fatality rates in nosocomiall outbreaks of Legionnaires' disease can exceed 40\%[46]. Hospitals caring for immunocompromised patients such as organ or bone marrow transplant recipients are at increased risk of outbreaks of Legionnaires' disease[47]. However, our understanding of the ecology and epidemiology of Legionella within hospital water systems[48] has improved. Other identified sources of nosocomial Legionnaires' disease that have been reported include contaminated cooling towers that were located near to a hospital ventilation air intake[49], respiratory therapy equipment that was cleaned with unsterilized tap water[50], ice machines[51] and aspiration of contaminated water associated with nasogastric feeding or swallowing disorders[52]. Legionnaires' disease is an uncommon form of pneumonia. The disease has no particular clinical features that clearly distinguish it from other types of pneumonia, and laboratory investigations must therefore be carried out in order to obtain a diagnosis. This diagnostic possibility should be pursued using appropriate diagnostic methodes and a case definition. The case definitions for nosocomial Legionnaires' disease summarized[53]:

- Definite nosocomial - Legionnaires' disease in a person who was in hospital for 10 days before the onset of symptoms.

- Probable nosocomial - Legionnaires' disease in a person who was in hospital for 1-9 of the 10 days before the onset of symptoms, and either became ill in a hospital associated with one or more previous cases of Legionnaires' disease, or yielded an isolate that was indistinguishable (by monoclonal antibody subgrouping or by molecular typing methods) from isolates obtained from the hospital water system at about the same time.

- Possible nosocomial - Legionnaires' disease in a person who was in hospital for 1-9 of the 10 days before the onset of symptoms in a hospital not previously known to be associated with any case of Legionnaires' disease, and where no microbiological link has been established between the infection and the hospital (or the residential institution).

\section{Epidemiology}

There is no evidence of person-to-person spread of Legionnaires' disease, infection being acquired primarily by inhalation of aerosol containing viable organisms or, particularly in immunocompromised patients, by aspiration of bacteria in water. L. pneumophila is the major cause of outbreaks (91.5\%) and serogroup 1 (sg1) is the predominant serotype (84.2\%)[55, 56]. The incidence of Legionnaires' disease depends on several factors, including the extent of contamination of the water reservoir by the organism [57, 3], susceptibility of the population exposed to that water, and the degree or intensity of the exposure of the patient to the water reservoir.

\subsection{Risk Factors for Developing Nosocomial Legionnaires' Disease}

The patient populations, the mode of transmission and potential environmental reservoirs are key issues when considering the likely occurrence of hospital legionellosis. Factors that render patients at higher risk of acquiring Legionella spp. infection comprise advanced age, underlying comorbidity, including alcoholism, diabetes, chronic obstructive pulmonary disease and Cancer (especially lung cancer or leukaemia), and cigarette smoking, and either corticosteroid or other forms of immunosuppressive therapy $[57,3]$. Legionnaires' disease is considered a very rare cause of pneumonia in children immunosuppressed and all neonates were hospital-acquired[58, 14]. Surgery is a major predisposing factor in nosocomial infection, with transplant recipients at the highest risk. Transplant recipients, including renal and non-renal transplants, are highly susceptible to infection. In some series of infections in liver transplant recipients, Legionella spp. are among the predominant pathogens, perhaps associated with simultaneous splenectomy for associated hypersplenism[59]. AIDS patients may also be at increased risk. However, Legionnaires' disease even severe cases may occur in 
previously healthy subjects and the absence of underlying disease should not be a reason to exclude the diagnosis[57]. In one series of hospitalized patients, Legionnaires' disease occurred more frequently in middle-aged men without predisposing factors, excepting that of excess alcohol intake[60].

Table 1. Legionella species and serogroups[54]

\begin{tabular}{|c|c|c|}
\hline Legionella species & Serogroups & $\begin{array}{c}\text { Association with } \\
\text { clinical cases }\end{array}$ \\
\hline L. adlaidensis & & Unknown \\
\hline L. anisa & & Yes \\
\hline L. bleiardensis & & Unknown \\
\hline L. birminghamensis & & Yes \\
\hline L. bozemanae & 2 & Yes \\
\hline L. brunensis & & Unknown \\
\hline L. busanensis & & Unknown \\
\hline L. cherrii & & Unknown \\
\hline L. cincinnatiensis & & Yes \\
\hline L. drancourtii & & Unknown \\
\hline L. dresdenensis & & Unknown \\
\hline L. drozanskii & & Unknown \\
\hline L. dumoffii & & Yes \\
\hline L. erythra & 2 & Yes \\
\hline L. fairfieldensis & & Unknown \\
\hline L. fallonii & & Unknown \\
\hline L.feeleii & & Yes \\
\hline L. geestiana & & Unknown \\
\hline L. genomospecies 1 & & Unknown \\
\hline L. gormanii & & Yes \\
\hline L. gratiana & & Unknown \\
\hline L. gresilensis & & Unknown \\
\hline L. hackeliae & 2 & Yes \\
\hline L. israelensis & & Unknown \\
\hline L. jamestowniensis & & Unknown \\
\hline L. jordanis & & Yes \\
\hline L. lansingensis & & Yes \\
\hline L. londiniensis & 2 & Unknown \\
\hline L. longbeachae & 2 & Yes \\
\hline L. lytica (comb. Nov.) & & Unknown \\
\hline L. maceachernii & & Yes \\
\hline L. micdadei & & Yes \\
\hline L. moravica & & Unknown \\
\hline L. nautarum & & Unknown \\
\hline L. oakridgensis & & Yes \\
\hline L. parisiensis & & Yes \\
\hline L. pneumophila & 16 & Yes \\
\hline L. quateirensis & & Unknown \\
\hline L. quinlivanii & 2 & Unknown \\
\hline L. rowbothamii & & Unknown \\
\hline L. rubrilucens & & Unknown \\
\hline L. sainthelensi & 2 & $Y e s$ \\
\hline L. santicrucis & & Unknown \\
\hline L. shakespearei & & Unknown \\
\hline L. spiritensis & 2 & Unknown \\
\hline L. steigerwaltii & & Unknown \\
\hline L. taurinensis & & Unknown \\
\hline L. tusconensis & & Yes \\
\hline L. wadsworthii & & $Y e s$ \\
\hline L. waltersii & & Unknown \\
\hline L. worsleiensis & & Unknown \\
\hline L. yabuuchiae & & Unknown \\
\hline
\end{tabular}

\subsection{Mode of transmission}

The transmission of L. pneumophila is associated with the use of water. Legionnaires' disease can be acquired by the inhalation of droplets $(1-5 \mu \mathrm{m}$ diameter) containing aerosolized organisms[61]. Less commonly, exposure to contaminated tap water has been reported as a cause of postoperative sternal wound infection. Aerosol formation, aspiration and direct installation of bacteria in the lungs in connection with manipulation of the respiratory tract are the most common means of Legionella infection in hospitals enviroment[13]. Showering with aerosol formation is often maintained to be a frequent infection route for Legionella in hospitals. Surprisingly enough, some studies show that showering can prevent Legionnaires' disease[13]. The explanation given is that patients who take showers are often less ill than bed-ridden patients and therefore less at risk through aspiration. Prospective studies show that showering is not associated with nosocomial Legionnaires' disease[62] .The most important risk factor for nosocomial pneumonia is aspiration[63]. Foreign bodies that involve the oropharynx are the most important risk factors for microaspiration[63]. In patients with chronic obstructive pulmonary disease (COPD), the protective function of the airways is impaired and the disease is associated with aspiration[63]. Even a tap-water facility with a low Legionella level can cause the disease in immunocompromised patients[64]. Water droplets on medical equipment that are passed down into the lungs may be infected with Legionella[62]. Since 1982, epidemiological studies have revealed that the primary source of infection for Legionnaires' disease in hospitals is via infected water[13]. Legionella can be introduced into the airways by means of contaminated Puritan nebulisers. It is recommended that sterile water be used for flushing nasogastric tubes in order to prevent nosocomial Legionnair es' disease[62]. A potential mechanism by which $L$. pneumophila might be transmitted via ingestion is that of bacteremic spread after penetration of the gastrointestinal tract. Diarrhea may be a prominent symptom Legionnaires' disease. Although comparative studies have failed to conforme a predilection for gastrointestinal symptoms in $L$. pneumophila as compared with pneumonias of other ethiology these early clinical observations are compatible with the possibility that the gastrintestinal tract was the portal of entry. Evidence to support ingestion in humans as a mode of transmission in scanty[62].

\section{Clinical manifestations}

Legionella infection of man (legionellosis) can vary from a mild flu-like illness to severe life-threatening pneumonia[ 57]. L. pneumophila is the second most frequent cause of severe community acquired pneumonia after thepneumococ cus. The illness has become increasingly recognized, less severely ill patients are seen earlier in the course of the disease[65]. Thus, clinical manifestations (fever, headache, diarrhea, hyponatremia) of hospital -acquired Legionnaires' disease were found to be less pronounced than for those with 
community-acquired Legionnaires' disease[66]. Pneumonia is the predominant clinical syndrome. The disease presents with a broad spectrum of illness, ranging from a mild cough and low-grade fever to stupor, respiratory failure, and multiorgan failure. Early in the illness, patients have nonspecific symptoms including fever, malaise, myalgias, anorexia, and headache. The temperature often exceeds $40^{\circ} \mathrm{C}$. The cough is only slightly productive. Chest pain, occasionally pleuritic, can be prominent and, when coupled with hemoptysis, may mistakenly suggest pulmonary emboli. Gastrointestinal symptoms are prominent, especially diarrhea, which occurs in 20 to 40 percent of cases. The stool is watery rather than bloody. The physical findings are those of pneumonia. The most common presentation of legionellosis is pneumonia which is often severe but almost any manifestation of the disease has been seen ranging from a mild self-limiting flu-like illness called Pontiac fever to any extrapulmonary affection to multi organ failure and death[66].

\subsection{Pontiac Fever}

A non pneumonic from disease associated with Legionella called Pontiac Fever has been described. It is an acute, self-limited illness, with "flu-like" symptoms. Numerous comparative studies of both community-acquired and nosocomial legionellosis show the clinical, radiological and laboratory features to be nonspecific [67, 57, 3]. The illness is characterized by a high attack rate of greater than 70 to $90 \%$ of exposed persons and an incubation period (typically 30 to 90 hours, with an average of $36 \mathrm{~h}$ )[68]. In addition, many persons who are infected with Legionella, as proven by seroconversion, will remain asymptomatic[69]. The illness typically resolves without complications within two to five days[68]. Upper or lower respiratory tract symptoms have not been associated with this illness. No additional information on Pontiac fever was located. Age, gender and smoking do not seem to be risk factors[68]. Rather, Pontiac Fever seems to affect preferentially young subjects: the age of cases was 36 to 39 years in the original Pontiac episode[68], and age medians during different documented epidemics were 29, 30 and 32 years[68]. Approximately $25 \%$ of cases are nosocomial in origin; the remainder is community-acquired[70]. Mortality is approximately $40 \%$ in patients with nosocomial infections and may be even higher in immunosuppressed patients[71].

\subsection{Legionnaires' Disease}

The clinical manifestation of Legionnaires' disease is quite varied and typically appears after 2 to 10 day incubation period[14]. There is an abrupt onset of a nonproductive cough (90\%)[2], malaise, myalgia, anorexia, and headache typically occur within 48 hours. These symptoms are usually accompanied by a rapidly rising fever that frequently reaches $39^{\circ} \mathrm{C}$ or $40^{\circ} \mathrm{C} 72$ ]. Chills may also occur with the fever. A dry cough is typically present in the early stages of the illness. Although the cough may become productive with minimally or moderately purulent sputum within several days, hemoptysis is rarely observed. Other common early features of the illness include neurologic abnormalities (e.g.,confusion, disorientation, lethargy) and gastrointestinal symptoms (e.g., nausea, vomiting, watery diarrhea)[2]. As the illness progresses, chest pain (often pleuritic), dyspnea, and respiratory distress may be observed. Nearly $25 \%$ of patients will exhibit some mental changes frequently confusion and disorientation. Agitation, hallucinations, depression, delirium and coma have been reported, although less frequently. Seizures, cerebellar dysfunction, and peripheral neuropathy are rare.

\subsection{Extrapulmonary Diseases}

Extrapulmonary diseases resulting from Legionnaires' disease are rare, but the clinical manifestations are often dramatic[73]. Since the index of suspicion is low, these infections can easily be overlooked. Legionella species have been implicated in cases of sinusitis[74], cellulitis[75], pancreatitis[76], brain abscess[72], acalculous cholecystitis [77] and myositis[76]. Typically, extrapulmonary infections occur concurrently with pneumonia and are believed to result from bacteremia[73]. The most common extrapulmon ary site is the heart, with numerous reports of myocarditis, pericarditis postcardiotomy syndrome, and prosthetic-valve endocarditis[78]. Most such cases were acquired in the hopital. Interestingly, in many cases there was no overt pneumonia[78]; the cardiac infections may have been caused by the entry of contaminated water into postoperative sternal wound or a mediastinal tube insertion site. Legionella wound infections developed in several patients after cardiothoracic surgery; foreign bodies such as sutures or drainage tubes may have promoted the development of infection.

\section{Pathogenicity and Virulence Factors}

Legionella species are not per se adapted to the human host. That they cause disease in humans is essentially an accident of nature; the pathogenic mechanisms have evolved to enable legionellae to survive in their protozoal host also enabling them to multiply in alveolar macrophages.

\subsection{Pathogenicity for Humans}

Infection in human occurred following inhalation of fine aerosol containing organisms that were both viable and virulent. Once within the alveoli, the legionellae are taken up by alveolar macrophages where they multiply[79]. As a result of these multiplications in polymorphonuclear neutrophils (PMN), more alveolar macrophages and peripheral blood monocyte-macrophages[80], where the bacteria evade fusion of the phagosome to lysosome, although the mechanism maybe different in some aspects. The pathogenesis of legionellosis is largely due to the ability of $L$. pneumophila to invade and grow within alveolar macrophages[81], and it is widely believed that this ability results from a prior adaptation to intracellular niches in 
nature[82].Without lessening the importance of intracellular infection; it is likely that additional factors contribute to the survival of L. pneumophila in humans[83].

\subsection{Properties of Potential Virulence Factors}

A number of virulence factors have been described for to genes L. pneumophila and gene products that play a role in the infection of mammalian and protozoan cells. The study of virulence factors in such diverse hosts has led to much speculation on the evolution of intracellular pathogens. Legionellae are intracellular pathogens of macrophages, by which they are phagocytosed in a process involving the complement fragment $\mathrm{C} 3$ and the monocyte complement receptors CR1 and CR3[79]. Both virulent and non-virulent strains are phagocytosed, remaining intact inside the phagocytes. Virulent strains can multiply inside the phagocytes and are able to inhibit the fusion of phagosomes with lysosomes; non-virulent strains do not multiply[84]. This interaction provides an excellent selective pressure for the acquisition of factors facilitating intracellular survival and, subsequently, infection. In 1989, the first virulence associated gene of $L$. pneumophila was detected by site-specific mutagenesis[3]. This gene, designated mip for macrophage infectivity potentiator, encodes a $24-\mathrm{kDa}$ surface protein (Mip)[85]. Mip is a prokaryotic homolog of the FK506-binding proteins and exhibits peptidylprolyl -cis/trans isomerase activity[86]. Subsequently, mip-like genes have been detected in other species of Legionella and other bacteria[3]. The exact function of Legionella Mip in vivo remains to be established[87]. Genes within the loci encoding the type IV secretion system of $L$. pneumophila were the first factors detected that were essential for infection of the host cell[3, 88]. These loci comprise 25 genes in two separate regions of the Legionella chromosome and have been named Dot/Icm (defective for organelle trafficking/intracellular multiplication)[89]. This type IV secretion system encodes factors involved in the assembly and activation of conjugal transfer of plasmid DNA[85]. L. pneumophila utilizes these operons to deliver virulence factors required for entering the host cell in a manner that initiates the infectious process. It is postulated that the system delivers a protein during phagocytosis that diverts the phagosome from the endocytic pathway[90]. The only secreted substrate that has been identified for the Dot/Icm system is DotA, a polytopic membrane protein[91]. Genes encoding the loci for type II secretion systems are required for unrestricted intracellular growth of L. pneumophila[92]. These genes were detected in L. pneumophila by analysis of mutants defective in type IV pilus formation[93]. The two genes that have been analyzed the most extensively are pilE (pilin protein) and pilD (prepilin peptidase)[94]. The pilE gene/pilin protein is not required for intracellular growth but may be involved in attachment to the host cell[95]. The pilD gene encodes the prepilin peptidase and is essential for pilus production and type II secretion of proteins[95].

\section{Diagnosis of Legionnaires' Disease}

\subsection{Diagnosis Radiology and Biological}

Legionnaire's disease is often classified as an "atypical pneumonia" based on the dogma that chest radiographic findings are neither lobar nor consolidating, as in the classic pyogenic pneumonias[96]. Chest radiographs typically demonstrate an initial unilateral alveolar infiltrate; however, many patterns have been reported[37]. Bilateral patterns are seen in nearly $50 \%$ of patients, and pleural effusions are detected in nearly one half of patients as well[70]. Resolution of infiltrates is frequently slow and lags behind clinical response. Leukocytosis of greater than $20.000 / \mathrm{mm}^{3}$ occurs in $10-20 \%$ of patients[70]. Hyponatremia is seen more with Legionnaires' disease than with other types of pneumonia and is most likely secondary to salt and water loss versus inappropriate antidiuretic hormone secretion. Hypophosphotemia, microhematuria, proteinuria and abnormal liver function tests are infrequent[70]. Analysis of the cerebrospinal fluid is generally within normal limits, but there are occasional reports of elevated protein or pleocytosis[37].

\subsection{Bacteriological Diagnosis}

Although diagnostic methods have improved since $L$. pneumophila was first described in 1976, no currently available test is able to diagnose all Legionella spp. in a timely fashion with a high degree of sensitivity and specificity. Most of the data are applicable to $L$. pneumophila, since sensitivity and specificity estimates for non-pneumophila species are not known[14]. The clinical symptoms of infection with Legionella are indistinguishable from the symptoms of other causes of pneumonia[38]. Accurate diagnostic methods are therefore needed to identify Legionella, and to provide timely and appropriate therapy. To improve diagnosis, specialized laboratory tests must be carried out, by the clinical microbiology laboratory, on patients in a high-risk category. Since 1995, diagnostic tests for legionellosis have changed significantly. The following laboratory methods are currently used for diagnosing Legionella infections[97]:

\subsubsection{Culture}

Isolation of Legionella spp., which has a specificity of $100 \%$, is considered the gold standard for diagnosis of Legionnaires' disease[14]. Culture diagnosis requires special media, adequate processing of specimens, and technical expertise (Table 2). Several days are required to obtain a positive result, with most Legionella spp. colonies being detected within 7 days[14]. The standard medium used to culture legionellae is buffered charcoal yeast extract (BCYE) agar supplemented with a-ketoglutarate, with or without antimicrobial agents[14]. This medium provides iron and L-cysteine, both of which are essential for the growth of legionellae[98]. 
Table 2. Diagnostic tests for Legionella infection[98]

\begin{tabular}{|c|c|c|c|c|c|}
\hline Test & $\begin{array}{c}\text { Turnaround } \\
\text { time }\end{array}$ & $\begin{array}{c}\text { Sample } \\
\text { type }\end{array}$ & $\begin{array}{c}\text { Sensitivity, } \\
\%\end{array}$ & $\begin{array}{c}\text { Specificity, } \\
\%\end{array}$ & Comments \\
\hline Culture & 3-7 Days & $\begin{array}{l}\text { LTR } \\
\text { Blood }\end{array}$ & $\begin{array}{c}<10-80 \\
\quad<10\end{array}$ & $\begin{array}{l}100 \\
100\end{array}$ & $\begin{array}{c}\text { Detects all species and } \\
\text { serogroups } \\
\text { Too insensitive for clinical use }\end{array}$ \\
\hline $\begin{array}{c}\text { Direct fluorescent } \\
\text { antibody staining }\end{array}$ & $<4 \mathrm{~h}$ & LRT & $25-70$ & $>95$ & Technically demanding \\
\hline Antigen detection & $<1 \mathrm{~h}$ & Urine & $70-90$ & $>95$ & $\begin{array}{l}\text { Only reliable for detection of } \\
\text { Legionella } \\
\text { pneumophila serogroup } 1\end{array}$ \\
\hline $\begin{array}{l}\text { Serological } \\
\text { testing }\end{array}$ & 3-10 weeks & Serum & $60-80$ & $>95$ & $\begin{array}{c}\text { Must test both acute- and } \\
\text { convalescent-phase serum } \\
\text { samples; single titer results can } \\
\text { be misleading }\end{array}$ \\
\hline \multirow{3}{*}{ PCR } & \multirow{3}{*}{$<4 \mathrm{~h}$} & LRT & $80-100$ & $>90$ & $\begin{array}{l}\text { No commercially available assay } \\
\text { for testing clinical samples; } \\
\text { detects all species and serogroups }\end{array}$ \\
\hline & & Serum & $30-50$ & $>90$ & - \\
\hline & & Urine & $46-86$ & $>90$ & - \\
\hline
\end{tabular}

The antibiotics most commonly added are polymyxin to control Gram-negative growth, anisomycin against yeasts, and cefamandole or vancomycin against Gram-positive bacteria. Vancomycin should be chosen if culture is aimed at species other than L. pneumophila, because cefamandole inhibits some Legionella spp. that does not produce beta-lactamases[14]. Legionellae can be isolated from a variety of sample types, although lower respiratory tract secretions (e.g., sputum and bronchoscopy samples) are the samples of choice. A major limitation of sputum culture is that less than one-half of patients with Legionnaires' disease produce sputum. Some patients with Legionnaires' disease produce sputum that has relatively little purulence; these samples may be rejected by laboratories that discard sputum samples containing few polymorphonuclear leukocytes[14].

\subsubsection{Direct Immuno Fluorescence Assays}

Direct immunofluorescence assays (DFAs) using antibody conjugated with a fluorochrome require 2-3 hours to complete the staining procedure. DFAs for Legionella species other than L. pneumophila should not ordinarily be used. DFA of sputum remains positive for 2-4 days after the initiation of the specific legionellosis antibiotic therapy, and often for a longer period in cases of a cavitary pulmonary disease[99]. Reported sensitivities of DFA staining vary, are consistently less than that of culture, and are less precisely known for species other than L. pneumophila. DFA has been used successfully with expectorated sputum, endotracheal suction aspirates, lung biopsies and transtracheal aspirate[97]. Pleural fluid examination in patients with legionellosis by culture or DFA rarely yields positive results, but has occasionally been helpful. Between $25 \%$ and $70 \%$ of patients with culture-proven legionellosis have positive DFA for L. pneumophila, and the test's specificity is higher than $99.9 \%$. Therefore, a negative result does not rule out legionellosis but a positive result is almost always diagnostic, provided that the slide is read correctly. Cross-reactions may be less of a problem when monoclonal-antibody DFA agents are used. Problems with sensitivity and specificity have limited the use of DFA staining, and a positive DFA result in the absence of other supporting evidence is now generally not accepted as sufficient for the diagnosis of Legionella infection[98].

\subsubsection{Serological Testing}

Serological testing for Legionella infection is a valuable epidemiological tool but has little impact on clinical decision making because of the time delay before a result is available. The indirect immunofluorescence assay (IFA) was used to detect antibodies in patients from the Philadelphia outbreak and was instrumental in determining the cause of the illnesses. Since then, a number of serologic test methodologies has been developed to detect antibodies to Legionella spp. of the various antibody detection methods that are available, Enzyme immunoassay (EIA) and microagglutination have also been used to detect antibodies to the Legionnaires' disease bacterium[3]. An indirect hemagglutination assay has been used for diagnosis of Legionnaires' disease due to L. pneumophila serogroups 1 to 4[3]. The rapid microagglutination test has some advantages over immunofluorescence, such as the ease of testing a large number of samples and the early appearance of agglutinating antibodies. Additional factors to consider in the serologic diagnosis of Legionnaires' disease are the use of an anti-human immunoglobulin which recognizes immunoglob ulin $\mathrm{G}(\operatorname{IgG}), \operatorname{IgM}$, and $\operatorname{IgA}[100]$. These antibody responses may be serogroup specific or may react with an antigen common to L. pneumophila; therefore, it is not possible to reliably determine the serogroup or species causing infection[3]. Other studies have shown that, in many patients with legionellosis, the immune response is primarily $\operatorname{IgM}$ and that IgM tests must thus be included for optimal 
sensitivity. Seroconversion may take several weeks, which is a major limitation of serological testing[14]. Approximately 25 to $40 \%$ of patients with Legionnaires' disease seroconvert within the first week after the onset of symptoms[44]. In most cases, a 4-fold increase in antibody titer is detected within 3 to 4 weeks, but in some cases, this may take more than 10 weeks. Acute-phase reciprocal IFA antibody titers of 256 in the presence of pneumonia were once considered sufficient for a presumptive diagnosis, but this has been shown to be unreliable, given the high prevalence of Legionella antibody positivity in persons without clinical evidence of legionellosis[4]. There is virtually no role for testing single serum samples. Another disadvantage of serological testing is the inability to accurately detect all Legionella species and serogroups.

Although seroconversion to L. pneumophila serogroup 1 is generally regarded as being highly predictive of disease, the sensitivity and specificity of seroconversion to other species and serogroups has not been rigorously confirmed. Furthermore, cross-reactive antibody formation among members of the family Legionellaceae can make it difficult to determine the infecting species or serogroup[98].

\subsubsection{Urinary Antigen Detection}

The detection of antigens from L. pneumophila in an infected person's urine is considered a reliable measure of the disease. An antigen excreted with urine has been characterized as heat-stable, resistant to enzymatic cleavage, and of about $10 \mathrm{kDa}$ molecular weight[99]. These characteri stics are typical for lipopolysaccharide components. $L$. pneumophila is now divided into at least 16 serogroups and several monoclonal subgroups[101]. Legionella antigenuria can be detected as early as 1 day after onset of symptoms and persists for days to weeks[98]. In one instance, excretion of antigen was documented to occur for more than 300 days[102]. The presence of antigen in the urine is a strong indicator of the disease, and a patient may have a positive response for several months following the disease. Indeed, all assays for the detection of $L$. pneumophila urinary antigens show sufficient recognition of the antigens which are homologous to the serogroup/monoclonal subgroup used as immunogen for preparation of the antisera, i.e. $L$. pneumophila sg $1[103,104]$. The sensitivity of urinary antigen detection appears to be associated with the clinical severity of disease[105]. With respect to the sensitivity for $L$. pneumophila sg 1 infections, all assays are able to detect more than $92 \%$ of cases identified by culture[103]. The major disadvantage with these tests is their inability to reliably detect organisms other than $L$. pneumophila serogroup 1[98].

\subsubsection{Nucleic Acid Amplification}

Over the last years, detection of nucleic acid has been more frequently used to identify Legionella in clinical samples. The first assay designed to detect the DNA of $L$. pneumophila was a radiolabeled ribosomal probe specific for all strains of Legionella spp[3]. PCR enables specific amplification of minute amounts of Legionella DNA, provides results within a short time frame, and has the potential to detect infections caused by any Legionella species and serogroup[38]. An important feature of Legionella PCR is that the method can potentially detect all serogroups of L. pneumophila and is therefore useful in the early diagnosis of infections, particularly in nosocomial cases[106]. PCR methods could have important economic benefits. Their use in outbreaks of legionellosis could help to rapidly rule out implicated sites, thereby minimizing lost revenue and allowing resources to be diverted to areas that need further investigation. Until the diversity and distribution of legionellae are better understood, results from methods other than culture should be interpreted cautiously. PCR has been successfully used to detect Legionella DNA in a range of environmental and clinical samples. When testing samples from the lower respiratory tract, PCR has repeatedly been shown to have sensitivity equal to or greater than culture[107]. Indeed, PCR could be considered the test of choice for patients who produce sputum. The role of PCR for testing other sample types is less clear. Legionella DNA can be detected in urine, serum, and leukocyte samples obtained from patients with legionnaires disease with sensitivities of $30 \%$ to $86 \%[108]$. The sensitivity of PCR is likely to increase when testing samples that are obtained early in the course of illness and when testing more than 1 sample type from each patient[109].

\section{Prevention and Control Measures}

Prevention strategies in health-care facilities in which no cases of nosocomial legionellosis have been identified have differed depending on the immunologic status of the patients, the design and construction of the facility, the resources available for implementing prevention strategies, and state and local regulations. At least two strategies are practiced with regard to the most appropriate and cost-effective means of preventing nosocomial legionellosis, especially in hospitals in which no cases or only sporadic cases of the illness have been detected.

The first approach is based on periodic, routine culturing of water samples from the hospital's potable water system for the purpose of detecting Legionella spp.

The second approach to preventing and controlling nosocomial legionellosis involves:

- Maintaining a high index of suspicion for legionellosis and appropriately using diagnostic tests for legionellosis in patients who have nosocomial pneumonia and who are at high risk for developing the disease and dying from the infection ;

- Initiating an investigation for a hospital source of Legionella spp. upon identification of one case of definite or two cases of possible nosocomial Legionnaires disease;

- Routinely maintaining cooling towers and using only sterile water for the filling and terminal rinsing of nebulizati 
on devices;

The indications for a full-scale environmental investigation to search for and subsequently decontaminate identified sources of Legionella spp. in hospital environments have not been clarified, and these indications probably differ depending on the hospital. In hospitals in which as few as one to three nosocomial cases are identified during a period of several months, intensified surveillance for Legionnaires disease has frequently identified numerous additional cases. This finding suggests the need for a low threshold for initiating an investigation after laboratory confirmation of cases of nosocomial legionellosis. However, when developing a strategy for responding to such identification, infection-control personnel should consider the level of risk for nosocomial acquisition of, and mortality from, Legionella spp. infection at their particular hospital.

\subsection{Assessing the Contamination of the Hot Water Distribution System}

The degree of contamination with L. pneumophila of the hot water distribution system should be assessed in a standardized fashion. The investigation of the hot water distribution system should begin on the ward where the index case was located. The conventional plate culture method described in the standard International Organization for Standardization (ISO) 11731-2-2004 is a very important technique for the detection of Legionella spp. because it is the currently used standard method and it provides strains for epidemiological studies. At the moment, the standard ISO 11731-2-2004 concerning the detection and enumeratio $\mathrm{n}$ of Legionella spp. and L. pneumophila on waters is also used to detect these bacteria on sewage and sludge.

\subsection{Disinfection of Water Distribution Systems for Legionella}

Water distribution Systems are the primary reservoirs for Hospital-acquired Legionnaires' disease. Prevention of hospital-acquired Legionnaires'disease has been accomplished by disinfecting hospital water distribution systems, especially the hot water recirculating. After detection of unacceptable high levels of legionellae effective decontamination and maintenance of water are critical for prevention of outbreaks of legionellosis. In the recent years a number of methods for controlling the growth of Legionellae in drinking water supply systems: thermal (super heat and flush), hyperchlorination, copper-silver ionization, ultraviolet light sterilization, ozonation, and instantaneous steam heating systems[110]. Disinfection modalities can be classified as either focal or systemic in their application[111]. Focal disinfection refers to disinfection directed at a portion of water distribution system, usually the incoming water and the outlets. Focal disinfenction approaches include ultrat-violet light and instantaneous heating systems that are modular and easy to install. However, these disinfenction systems are already heavily colonized with $L$. pneumophila that will persist in the biofilm throughout the water distribution system. Therefore, focal disinfection can eliminate Legionella only at the point of contact[111]. Systemic disinfection refers to disinfection directed at the entire water distribution system by providing a disinfection residual that is bacteriostatic or bactericidal throughout the system, especially the distal sites and stagnant areas. These modalites include continuous hyperchlorination and copper/silver ionization. Thermal eradication (superheat and flush) is a systemic disinfection modality, however, the duration of disinfection is only short-term. Each systemic modality is highly dependent on adequate water distribution throughout the system. Failure of the disinfectant to reach the colonized area will affect the overall succeed of the method[111].

\subsubsection{Thermal Eradication (Superheat and Flush)}

Legionella species survive for months in tap[112] but are susceptible to many disinfectants, moist heat, and dry heat. The bacteria have been killed at elevated temperatues with thermal death times (D-Values) of approximatelly 2 minutes at $60^{\circ} \mathrm{C}$ and 13,9 minutes at $55^{\circ} \mathrm{C}$. Raising the hot water temperature and flushing outlets was the first method successfully used for Legionella disinfection the "Superheat and flush" method can use in an outbreak situation, and still is used in some hospitals intermittently to supers widespread Legionella contamination. The water must attain a temperature of $70^{\circ} \mathrm{C}$ followed by flushing of all water outlets, faucets, and showerheads with hot water for 30 minutes to kill Legionella colonizing these sites. Special attention must be given to the plumbing material, which must be suitable for exposure to high temperatures[111]. The disadvantages to this method are the potential for scalding and the fact that many personnel are required to monitor distal sites, tank water temperatures, flushing times, and the requirement of considerable energy[113]. In addition, recolonization will occur within months because disinfection using this method is only temporary.

\subsubsection{Silver/Copper Ionisation}

Copper-silver ionization systems were installed on the hot-water distribution system. This system electrolytically generates copper and silver ions, which bind to the bacterial cell wall causing cell-wall disruption and lysis[114]. Copper and Silver ions kill L.pneumophila in vitro[115] and in vivo[116]. The precipitation of lime on the cathode due to the production of hydroxide ions is minimised by changing the polarisation of the electrodes. Another system working on the basis of silver ions introduces a solution containing silver ions into the water proportionally to the water consumed. Silver and copper ions are removed at each water outlet by a filter. One disadvantage is that silver and copper ions are not allowed for disinfection of drinking water in each country. Silver ions may cause corrosion of the system and, furthermore, the electrodes or the silver solution have to be replaced periodically[113].

\subsubsection{Ultraviolet light Irradiation}


A swift local bactericidal effect is achieved with ultraviolet light (UV light) in the course of 20 minutes[117]. Ultraviolet (UV light) irradiation of the water at 254 nanometres eradicates Legionella without the addition of chemicals to the water. Ultraviolet light kills Legionella by disrupting cellular DNA synthesis[118]. It can be positioned to disinfect the incoming water, or it can be installed at a specific place in the pipe system that services a designated area. UV treatment should not be used as the sole disinfection method, because no residual protection is given in the system. Legionellae released from biofilms near water outlets are not eradicated[94]. Additionally, UV lamps are susceptible to scale and sediment deposits. The system must be installed distally of the water site. Concomitant use of bacteriological filters is recommended, which also increases the costs. UV light is not recommended in water facilities that are already contaminated with Legionella[117].

\subsubsection{Ozone}

Ozone is used in Europe for water disinfection of certain hospital services. Ozone kills Legionella by disrupting cellular DNA synthesis. In 1988 Domingue et al. have shown experimentally to ozone $(0.1$ to $0.3 \mathrm{mg} / \mathrm{L})$ was able to eliminate $99 \%$ of $L$. pneumophila in 5 minutes[119]. Ozone is a well-known disinfectant that has been used for decades in water treatment. Low amounts of ozone are produced from aerial oxygen by corona discharge and injected into a bypass of the circulation system. A constant ozone concentration of $1-2 \mathrm{mg} / \mathrm{l}$ is required in water in order to bring about an adequate reduction in the Legionella concentration[117]. Ozone eradicates Legionella and destroys the biofilm throughout the system. Advantages of ozone include the residual protection, its decomposition to oxygen and not having to handle chemicals[113].

\subsubsection{Hyperchlorination}

Chlorine is an oxidizing agent that been successfully used as a disinfectant for controlling pathogens in domestic drinking water. Adding chlorine to water systems is a known method of controlling Legionella in both hot and cold water systems[117]. Hyperchlorination of water distribution systems requires the installation of a chlorinator. Shock chlorination is followed by continuous hyper-chlorination of the water raising chlorine levels throughout the system for one to two hours[111]. It is impossible to eradicate Legionella completely from the water system, and recontamination therefore takes place readily[117]. The method requires precise monitoring of the chlorine level and personnel to perform the work[117]. Chlorine can be used in the event of outbreaks or for long-term control of Legionella. Chlorine has no effect on Legionella in blind pipes, and over time it has a corrosive effect on pipe. Legionella forms a biofilm to gether with other microbes and amoebae in the pipe system. The bacteria in the biofilm are more resistant to biocides and heat treatment than freely circulating bacteria[111]. Hyperchlorination may cause human health problems. Levels of trihalomethanes tend to increase in the hot water system when chlorine levels exceed $4 \mathrm{mg} / \mathrm{L}[111]$.

\section{Conclusions}

Infection with Legionella remains an important cause of disease and death in the world. Diagnosis and treatment of legionnaires' disease should be targeted at patients at increased risk for illness and complications due to Legionella infection. Diagnostic tests for legionnaires' disease based on species other than L. pneumophila, serogroup 1, should be developed and tested. Recommendations for prevention of Legionnaires' disease should be focused on settings where there are persons at greatest risk for illness or serious outcome.

\section{REFERENCES}

[1] Strausbaugh LJ. Nosocomial respiratory infections. In: Mandel GL, Benet JE, Dolin R, eds. Principles and practice of infectious diseases. New York, NY: Churchill Livingstone, $2000 ; 3020-3028$.

[2] Benin, A. L., Benson, R. F., Arnold, K. E., Fiore, A. E., Cook, P. G., Williams, L. K., Fields, B. S., and Besser, R. E. An outbreak of travel-associated legionnaires disease and Pontiac fever: the need for enhanced surveillance of travel-associated legionellosis in the United States. Journal Infect Dis; 185(2):237-243, 2002.

[3] Fields, B. S., Benson, R. F. and Besser, R. E. Legionella and Legionnaires' disease: 25 years of investigation. Clin Microbiol Rev 15, 506-526, 2002.

[4] Plouffe, J. F. R., Breiman, R. F., Hackman, B. A., Salstrom, S. J., Marston, B. J., and Fields, B. S. Reevaluation of the definition of Legionnaires' disease: use of the urinary antigen assay. Clin Infect Dis; 20(5):1286-1291, 1995.

[5] Joly, J. R., and Alary, M. Occurrence of nosocomial Legionnaires' disease in hospitals with contaminated potable water supply. In: Barbaree JM, Breiman RF, Dufour AP, eds. Legionella: current status and emerging perspectives. Washington, DC: American Society for Microbiology:3, 1993.

[6] Levy, P. Y., Teysseire, N., Etienne, J., and Raoult, D. A. nosocomial outbreak of Legionella pneumophila caused by contaminated transesophageal echocardiography probes. Infect Control Hosp Epidemiol; 24(8):619-22, 2003.

[7] Yu, P. Y., Lin, Y. E., Lin, W. R., Shih, H. Y., Chuang, Y. C., Ben, R. J., Huang, W, K., Chen, Y. S., Liu, Y. C., Chang, F. Y., Yen, M. Y., Liu, C.C., Ko, W. C., Lin, H. H., Shi, Z. Y. The high prevalence of Legionella pneumophila contamination in hospital potable water systems in Taiwan: implications for hospital infection control in Asia. International Journal of Infectious Diseases; 12(4), 416-442, 2008.

[8] Osterholm, M. T., Chin, T. D., Osborne, D. O., Dull HB, Dean, A. G., Fraser, D. W., Hayes, P. S., and Hall, W. N. A 
1957 outbreak of Legionnaires' disease associated with a meat packing plant. Am. J. Epidemiol; 117(1):60-67, 1983.

[9] Thacker, S. B., Bennett, J. V., Tsai, T. F., Fraser, D. W., McDade, J. E., Shepard, C. C., Williams Jr., K. H., Stuart, W. H., Dull, H. B., and Eickhoff, T. C. An Outbreak in 1965 of Severe Respiratory Illness Caused by the Legionnaires' disease Bacterium. The Journal of Infectious Diseases; 138(4): 512-519, 1978.

[10] Glick, T. H., Gregg, M. B., Berman, B., Mallison, G., Rhodes, W. W. J. r., and Kassanoff, I. Pontiac fever. An epidemic of unknown etiology in a health department: I. Clinical and epidemiologic aspects. Am. J. Epidemiol; 107(2):149-60, 1978.

[11] Mermel, L. A., Josephson, S. L., Giogio, C. H., and Dempsy, J. Association of Legionnaires' disease with construction: contamination of potable water? Infection Control and Hospital Epidemiology; 16:76-81, 1995.

[12] Edelstein, P. H. Legionnaires'Disease. Clinical Infectious Diseases; 16, (6):741-747, 1993.

[13] Sabrià, M., and Yu, V. L. Hospital-acquired legionellosis: solutions for a preventable infection. Lancet Infect. Dis; 2(6): 368-373, 2002.

[14] Diederen, B. M. Legionella spp. and Legionnaires' disease. J Infect; 56(1):1-12, 2008.

[15] Kool, J. R., Fiore, A. E., Kioski, C. M., Brown, E. W., Benson, R. F., Pruckler, J. M., Glasby, C., Butler, J. C., Cage, G. D., Carpenter, J. C., Mandel, R. M., England, B., and Breiman, R. F. More than 10 years of unrecognised nosocomial transmission of Legionnaires' disease among transplant patients. Infect Control Hosp Epidemiol; 19(12):898-904, 1998.

[16] Yu, V. L. Nosocomial legionellosis. Curr Opin Infect Dis; $13: 385-388,2000$.

[17] Anbumani, S., Gururajkumar, A., and Chaudhury, A. Isolation of Legionella pneumophila from clinical and environmental sources in a tertiary care hospital. Indian $\mathrm{J}$ Med Res; 131:761-764, 2010.

[18] Ozerol, I. H., Bayrakta, M., Cizmeci, Z., Durmaz, R., Akbas, E., Yildirim, Z., Yologlu, S. Legionnaire's disease: a nosocomial outbreak in Turkey. J Hosp Infect; 62(1):50-57, 2006.

[19] Napoli, C., Fasano, F., Iatta, R., Barbuti, G., Cuna, T. and Montagna, M. T. Legionella spp. and legionellosis in southeastern Italy: disease epidemiology and environmental surveillance in community and health care facilities in community and healthcare facilities. BMC Public Health; 10:660, 2010.

[20] Chien, S. T., Hsueh, J. C., Lin, H. H., Shih, H. Y., Lee, T. M., Ben, R. J., Chou, S. T., Fong, C. M., Lin, Y. E., Tseng. L. R., Chiang, C. S. Epidemiological investigation of a case of nosocomial Legionnaires' disease in Taiwan: implications for routine environmental surveillance. Clin Microbiol Infect; 16(6):761-763, 2010.

[21] Lai, C. C., Tan, C. K., Chou, C. H, Hsu, H. L., Huang, Y. T., Liao, C. H., and Hsueh, P. R. Hospital-acquired pneumonia and bacteremia caused by Legionella pneumophila in an immunocompromised patient.Infection; 38(2):135-137, 2010.
[22] Stypulkowska-Misiurewicz, H., Pancer, K., Krogulska, B., Matuszewska, R. Outbreak of hospital acquired Legionnaires' disease in patients of ophthalmic ward. Nosocomial Legionella infections for the first time observed in Poland. Przegl Epidemiol; 61(4):657-665, 2007.

[23] Bou, R., Ramos, P. Outbreak of nosocomial Legionnaires' disease caused by a contaminated oxygen humidifier. J. Hosp Infect; 71:381-383, 2009.

[24] Group, J. B. Source of Legionnaires' disease Found in Cudahy Hospital. Todays TMJ4com/new, 2010.

[25] Palmore, T. N., Stock, F., White, M. D., Bordner, M., Michelin, A., Bennett, J. E., Murray, P. R., Henderson, D. K.. A cluster of nosocomial Legionnaires' disease linked to a contaminated hospital decorative water fountain. Infect Cont Hosp Epidemiol; 30(8):764-768, 2009.

[26] Brulet, A., Nicolle, M. C., Giard, M., Nicolini, F. E., Michallet, M., Jarraud, S., Etienne, J., and Vanhems, P. Fatal nosocomial Legionella pneumophila infection due to exposure to contaminated water from a washbasin in a hematology unit. Infect Control Hosp Epidemiol; 29(11):1091-1093, 2008.

[27] Alary, M. and Joly, J. R. Risk Factors for Contamination of Domestic Hot Water Systems by Legionellae. Applied and Environment Microbiology; 57(8):2360-2367, 1991.

[28] Fox, K. F., and Brown, A. Properties of the genus Tatlockia.Differentiation of Tatlockia (Legionella) maceachernii and micdadei from each other and from other legionellae. Can. J. Microbiol. 39:486-491, 1993.

[29] Garrity, G. M., Brown, A., and Vickers, R. M. Tatlockia and Fluoribacter: two new genera of organisms resembling Legionella pneumophila. Int. J. Syst. Bacteriol. 30:609-614, 1980.

[30] Benson, R. F., and Fields, B. S. Classification of the genus Legionella. Semin. Respir. Infect. 13(2):90-99, 1998.

[31] Fry, N. K., Warwick, S. N. Saunders, A., and Embley, T. M. The use of $16 \mathrm{~S}$ ribosomal RNA analyses to investigate the phylogeny of the family Legionellaceae. Journal of general Microbiology; 137(5):1215-1222, 1991.

[32] Kuroki, H., Miyamoto, H., Fukuda, K., Iihara, H., Kawamura, Y., Ogawa, M., Wang, Y., Ezaki, T., and Taniguchi, H. Legionella impletisoli sp. nov. and Legionella yabuuchiae sp. nov., isolated from soils contaminated with industrial wastes in Japan. Systematic and Applied Microbiology; 30 (4): 273-279, 2007.

[33] Koide, M., Furugen, M., Haranaga, S., Higa, F., Tateyama, M., Yamane, N., and Fujita, J., Characteristics of Legionella pneumophila serogroup 2 strains by colony morphology. Jpn. J. Infect. Dis. 61(6): 487-489, 2008.

[34] Lee, H. K., Shim, J. I., Kim, H. E., Yu, J. Y., and Kang, Y. H. Distribution of Legionella Species from Environmental Water Sources of Public Facilities and Genetic Diversity of L. pneumophila Serogroup 1 in South Korea. Applied and Environmental Microbiology; 76(19): 6547-6554, 2010.

[35] Jarraud, S., Reyrolle, M., Etienne, J. Legionella et Legionellose. In: Freney, J. Renaud, F. Hansen, W. Bollet, C. Eds. Précis de bactériologie Clinique. Paris: ESKA; 1389-1405, 2000. 
[36] Brenner, D. J., Feeley, J. C., and Weaver, R. E. Family VIII Legionellaceae. In Bergey's Manual of Systematic Bacteriology. Krieg NR, Holt JG (Eds). Williams and Wilkins, Baltimore, MD. (1):279. (As sited in EPA 1985), 1984.

[37] Nguyen, M. H., Stout, J. E., Yu, VL. Legionellosis. Infectious Disease Clinics of North America; 5(3):561-584, 1991.

[38] Guyard, C., and Low, D. E. Legionella infections and travel associated legionellosis. Travel Medicine and Infectious Disease; 9(4 ): 176-186, 2011.

[39] Buchrieser, C., and Buchrieser, C. Legionella: from protozoa to humans. Front Microbiol; 2(182): 1-3, 2011.

[40] Levin, A. S. Nosocomial legionellosis: prevention and management. Expert Review of Anti-Infective Therapy; 7(1): 57-68, 2009.

[41] Murga, R., Forster, T. S., Brown, E., Pruckler, J. M., Fields, B. S. and Donlan, R. M. Role of biofilms in the survival of Legionella pneumophila in a model potable-water system. Microbiology; 147(11): 3121-3126, 2001.

[42] Declerck, P. Biofilms: the environmental playground of Legionella pneumophila. Environmental Microbiology; 12(3): 557-566, 2010.

[43] Lasheras, A., Boulestreau, H., Rogues, A. M., Ohayon-courtes, C., Labadie, J. C., Gachie, J. P. Influence of amoebae and physical and chemical characteristics of water on the presence and proliferation of Legionella species in hospital water systems. American Journal of Infection Control; 34(8):520-525, 2006.

[44] Boccia, S., Laurenti, P., Borella, P., Moscato,U., Capalbo, G., Cambieri, A., Amore, R., Quaranta, G., Boninti, F., Orsini, M., Branca, G., Fadda, G., Romano-Spica, V., and Ricciardi, G. Prospective 3-year surveillance for nosocomial and environmental Legionella pneumophila: implications for infection control. Infect Control Hosp Epidemiol; 27(5):459-465, 2006.

[45] Squier, C. L., Stout, J. E., Krsytofiak, S., McMahon, J., Wagener, M. M., Dixon, B., and Yu VL. A proactive approach to prevention of health care-acquired Legionnaires' disease: the Allegheny County (Pittsburgh) experience. Am J Infect Control; 33(6):360-367, 2005.

[46] Fiore, A. E., Butler, J. C., Emori, T. G., and Gaynes, R. P. A survey of methods used to detect nosocomial legionellosiss among participants in the National Nosocomial Infections Surveillance System. Infection Control and Hospital Epidemiolog; 20(6): 412-416, 1999.

[47] Kool, J. L., Bergmire-Sweat, D., Butler, J. C., Brown, E. W., Peabody, D. J., Massi, D. S., Carpenter, J. C., Pruckler, J. M., Benson, R. F., and Fields, B. S. Hospital characteristics associated with colonization of water systems by Legionella and risk of nosocomial Legionnaires' disease: a cohort study of 15 hospitals. Infect Control Hosp Epidemiol; 20(12):798-805, 1999.

[48] O’Neill, E. and Humphreys, H. Surveillance of hospital water and primary prevention of nosocomial legionellosis: what is the evidence? Journal of Hospital Infection; 59(4): 273-279. 2005.

[49] Breiman, R. F., Cozen, W., Fields, B. S., Mastro, T. D., Carr, S. J., Spika, J. S., and Mascola, L. (1990). Role of air sampling in investigation of an outbreak of Legionnaires' disease associated with exposure to aerosols from an evaporative condenser. Journal Infect Dis; 161(6):1257-1266.

[50] Mastro, T. D., Fields, B. S., Breiman, R. F., Campbell, J., Plikaytis, B. D., and Spika, J. S. Nosocomial Legionaires' disease and use of medication nebulisers. J Infect Dis; 163(3):667-7, 1991.

[51] Graman, P. S., Quinlan, G. A, and Rank, J. A. Nosocomial legionellosis traced to a contaminated ice machine. Infect Control Hosp Epidemiol; 18(9):637-640, 1997.

[52] Venezia, R. A., Agresta, M. D., Hanley, E. M., Urquhart, K., and Schoonmaker, D. Nosocomial legionellosis associated with aspiration of nasogastric feedings diluted in tap water. Infect Control Hosp Epidemiol; 15(8):529-533, 1994.

[53] Lee, J. V., and Joseph, C. On behalf of the PHLS Atypical Pneumonia Working Group. Guidelines for investigating single cases of Legionnaires disease. Commun. Dis. Public Health; 5(2):157-162, 2002.

[54] Deutsche Sammlung von Mikroorganismen und Zellkulturen (DSMZ). 2011. German Collection of Micro-organisms and Cell Cultures. Accessed 14 March 2011. http://www.dsmz.de/microorganisms/bacterial_nomenclature info.php?genus=Legionella\&show_all_details=1.

[55] Lück, C. P., Jacobs, E., Roske, I., Schroter-Bobsin, U., Dumke, R., and Gronow, S. Legionella dresdenensis sp. nov. isolated from the river Elbe near Dresden in Germany. International Journal of Systematic and Evolutionary Microbiology; 2009.

[56] Yu, V. L., Plouffe, J. F., Pastoris, M. C., Stout, J. E., Schousboe, M., Widmer, A., Summersgill, J., File, T., Heath, C. M., Paterson, D. L., and Chereshsky, A. Distribution of Legionella species and serogroups isolated by culture in patients withs poradic community-acquired legionellosis: an international collaborative survey. The Journal of Infectious Diseases; 186(1):127-128, 2002.

[57] Roig, J., Rello, J. and Yu, V. L. Legionnaires' disease: a guide to diagnosis and therapy. Journal of Respiratory Diseases; 23(4): 229-234, 2002.

[58] Greenberg, D., Chiou, C. C., Famigilleti, R., Lee, T. C., Yu, V. L. Problem pathogens: paediatric legionellosis-implications for improved diagnosis. Lancet Infect Dis;6(8):529-535, 2006.

[59] Neumann, U. P., Langrehr, J. M., Kaisers, U., Lang, M., Schmitz, V., and Neuhaus, P. Simultaneous splenectomy increases risk for opportunistic pneumonia in patients after liver transplantation. Transplant International; 15(5): 226-232, 2002.

[60] Sopena, N., Sabria-Leal, M., Pedro-Botet, M. L., Padilla, E., Domínguez, J., Morera, J., and Tudela, P. Comparative study of the clinical presentation of Legionella pneumonia and other community acquired pneumonias. Chest; 113(5): 1195-1200, 1998.

[61] Pasculle, W. Update on Legionella. Clinical Microbiology Newsletter; 22(13): 97-101, 2000.

[62] Sarjomaa, M., Urdahl, P., Ramsli, E., Borchgrevink-Lund, C. F., Ask, E. Prevention of Legionnaires' disease in hospitals. Tidsskr Nor Laegeforen; 131(16):1554-1557, 2011. 
[63] Yu, V. L. Cooling towers and legionellosis: a conundrum with proposed solutions. Int. J. Hyg Environ Health; 211(3-4):229-234, 2008

[64] Exner, M., Kramer, A., Lajoie, L., Gebel, J., Engelhart, S., and Hartemann, P.(2005). Prevention and control of health care-associated waterborne infections in health care facilities. Am J Infect Control; 33(5 suppl 1): S26-40, 2005.

[65] García-Fulgueiras, A., Navarro, C., Fenoll, D., García, J., González-Diego, P., Jiménez-Buñuales, T., Rodriguez, M., Lopez, R., Pacheco, F., Ruiz, J., Segovia, M., Balandrón, B., and Pelaz, C. (2003). Legionnaires' disease outbreak in Murcia, Spain. Emerg Infect Dis; 9(8):915-291.

[66] Jespersen, S., Søgaard, O. S., Schønheyder, H. C., Fine, M. J., and Ostergaard, L. Clinical features and predictors of mortality in admitted patients with community-and hospital acquired legionellosis: a Danish historical cohort study. BMC Infect Dis; 10:124, 2010.

[67] Gupta, S. K., Imperieal, T. F. and Sarosi, G. A. Evaluation of the Winthrop University hospital criteria to identify Legionella pneumonia. Chest; 120(4): 164-1071, 2001.

[68] Tossa, P., Deloge-Abarkan, M., Zmirou-Navier, D., Hartemann, P., and Mathieu, L. Pontiac fever: an operational definition for epidemiological studies. BMC Public Health; 6: $112,2006$.

[69] Boshuizen ,H. C., Neppelenbroek, S. E., Van Vliet, H., Schellekens, J. F., Den Boer, J. W., Peeters, M. F., and Conyn-van Spaendonck, M. A. Subclinical Legionella infection in workers near the source of a large outbreak of Legionnaires disease. Journal Infect Dis; 184(4):515-518, 2001.

[70] Evenson, L. J. Legionnaires' disease. Fifth Prize Pape; 5(6) : 286-289, 1998.

[71] Sheffer, P. J., Stout, J. E., Wagener, M. M., Muder, R. R. Efficacy of new point-of-use water filter for preventing exposure to Legionella and waterborne bacteria. Am J Infect Control; 33(5 Suppl 1):S20-25, 2005.

[72] Jarraud, S., Reyrolle, M., Meugnier, H., Forey, F., and Etienne, J. Legionnaires' disease. Presse Med; $36(2 \mathrm{Pt}$ 2):279-287, 2007.

[73] Muder, R. R., and Yu, V. L. Infection due to Legionella species other than L. pneumophila. Clin Infect Dis;35(8):990-998, 2002.

[74] Lowry, P. W., and Tompkins, L. S. Nosocomial legionellosis: a review of pulmonary and extrapulmonary syndromes. Am J Infect Control; 21(1):21-27, 1993.

[75] Han, J. H., Nguyen, J. C., Harada, S., Baddour, L. M., and Edelstein, P. H. Relapsing Legionella pneumophila cellulitis: a case report and review of the literature. J Infect Chemother; 16(6):439-42, 2010.

[76] Edelstein, P. H. Legionnaires'Disease: History and Clinical Findings. IN, Legionella: Molecular Microbiology Book. 1-13, 2008.

[77] Earle, K. A., and Hoffbrand, B. I. Acalculous cholecystitis complicating Legionnaires' disease. $\mathrm{Br} \mathrm{J}$ Clin Pract; 44(12):783, 1990.

[78] Burke, P. T., Shah, R., Thabolingam, and R., Saba, S. Suspected Legionella induced perimyocarditis in an adult in the absence of pneumonia: a rare clinical entity. Tex Heart Inst J; 36(6):601-603, 2009.

[79] Khweek, A. A., and Amer, A. Replication of Legionella Pneumophila in Human Cells: Why are We Susceptible? Front Microbiol; 1:133, 2010.

[80] Dowling, J. N., Saha, A. K., and Glew, R. H. Virulence factors of the family Legionellaceae. Microbiol; 56(1): 32-60, 1992.

[81] Faucher, S. P., and Mueller, C. A., Shuman HA. Legionella pneumophila transcriptome during intracellular multiplication in human macrophages. Front Microbiol; 2:60, 2011.

[82] Jules, M. and Buchrieser, C. Legionella pneumophila adaptation to intracellular life and host response: clues from genomics and transcriptomics. FEBS Lett; 581(15): 2829-2832, 2007.

[83] Cianciotto, N. P. Pathogenicity of Legionella pneumophila. Int J Med Microbiol; 291(5):331-343, 2001.

[84] Horwitz, M. A. Toward an understanding of host and bacterial molecules mediating Legionella pneumophila pathogenesis. In: Barbaree JM, Breiman RF, Dufour AF. Legionella: current status and emerging perspectives. Washington, DC, American Society for Microbiology: 55-62, 1993.

[85] Swanson, M. S., and Hammer, B. K. Legionella pneumophila pathogenesis: a fateful journey from amoebae to macrophages. Annu. Rev. Microbiol. 54:567-613, 2000.

[86] Schmid, F. X. Prolyl isomerase: enzymatic catalysis of slow protein-folding reactions. Annu. Rev. Biophys. Biomol. Struct. 22:123-142, 1993.

[87] Köhler, R., Fanghänel, J., König, B., Lüneberg, E., Frosch, M., Rahfeld, J. U., Hilgenfeld, R., Fischer, G., Hacker, J., and Steinert, M. Biochemical and functional analyses of the Mip protein: influence of peptidylprolyl isomerase activity on the virulence of Legionella pneumophila. Infect Immun: 71(8); 4389-4397, 2003.

[88] Lammertyn, E. and Anné, J. Protein secretion in Legionella pneumophila and its relation tovirulence. FEMS Microbiol. Lett. 238(2): 273-279, 2004.

[89] Feldman, M., and Segal, G. A specific genomic location within the icm/dot pathogenesis region of different Legionella species encodes functionally similar but nonhomologous virulence proteins. Infect Immun; 72(8):4503-4511, 2004.

[90] Zink, S. D., Pedersen, L., Cianicitto, N. P., Abu-Kwaik, Y. The Dot/Icm type IV secretion system of Legionella pneumophila is essential for the induction of apoptosis in human macrophages. Infect Immun; 70(3): 1657-1663, 2002.

[91] Nagai, H., and C. Roy. The DotA protein from Legionella pneumophila is secreted by a novel process that requires the Dot/Icm transporter. EMBO J. 20(21):5962-5970, 2001.

[92] Rossier, O., Starkenburg, S. R., and Cianciotto, N. P. Legionella pneumophila type II protein secretion promotes virulence in the A/J mouse model of Legionnaires' disease pneumonia. Infect Immun; 72(1): 310-321, 2004.

[93] Stone, B. J., and Y. Abu Kwaik. Expression of multiple pili by Legionella pneumophila: identification and characterization of a type IV pilin gene and its role in 
adherence to mammalian and protozoan cells. Infect. Immun. 66(4):1768-1775, 1998 .

[94] Lin, Y. S., Stout, J. E., Yu, V. L., and Vidic, R. D. Disinfection of water distribution systems for Legionella. Semin Respir Infect; 13(2):147-159, 1998.

[95] Söderberg, M. A., Rossier, O., and Cianciotto, N. P. The Type II Protein Secretion System of Legionella pneumophila Promotes Growth at Low Temperatures. J Bacteriol; 186(12):3712-3720, 2004.

[96] Tan, M. J., Tan, J. S., Hamor, R. H. R., and Breiman, R. E. The radiologic manifestations of Legionnaires' disease. Chest; 117(2): 398-403, 2000.

[97] Stout, J. E., Rihs, J. D. and Yu, V. L. Legionella. In Manual of Clinical Microbiology, 8th edn, pp. 809-823. Edited by P. R. Murray, E. J. Baron, J. H. Jorgensen, M. A. Pfaller and R. H. Yolken. Washington, DC: American Society for Microbiology, 2003.

[98] Murdoch, D. R. Diagnosis of Legionella Infection. Clin Infect Dis; 36 (1): 64-69, 2003.

[99] Lück, P. C., Helbig, J. H., and Schuppler, M. Epidemiology and Laboratory Diagnosis of Legionella Infections. Journal of Laboratory Medicine; 26 (3/4): 174-182, 2002.

[100] Bangsborg, J. M., G. H. Shand, K. Hansen, and J. B. Wright. Performance of four different indirect enzyme-linked immunosorbent assays (ELISAs) to detect specific IgG, IgA, and IgM in Legionnaires' disease. APMIS; 102(7):501-508, 1994.

[101] Helbig, J.H., Benson, R.F., Pelaz, C., Jacobs, E. and Lück, P.C. Identification and serotyping of atypical Legionella pneumophila strains isolated from human and environmental sources. J. Appl Microbiol; 102(1): 100-105, 2007.

[102] Kohler, R. B., Winn, W. C., and Wheat, L. J. Onset and duration of urinary antigen excretion in Legionnaires' disease. Journal of Clinical Microbiology; 20(4):605-607, 1984.

[103] Helbig, J. H., Uldum, S. A, Lück, P. C., and Harrison, T.G. Dectetion of Legionella pneumophila antigen in urine simple by the BinaxNow immunochromatographic assay and comparaison with both Legionella urinary Enzyme Immunoassay (EIA) Biotest Legionella urin Antigen EIA. J. Med. Microbio. 50(6): 509-516, 2001.

[104] Guerrero, C., Toldos, C. M., Yague, G., Ramirez, C., Rodriguez, T., and Segovia, M. Comparison of diagnostic sensitivities of three assays (Bartels enzyme immunoassay \{EIA\}, Biotest EIA, and Binax NOW Immunochromatographic Test) for detection of Legionella pneumophila Serogroup 1 antigen in urine. J Clin Microbiol; 42(1): 467-668, 2004.

[105] Yzerman, E. P., Den Boer, J. W., Lettinga, K. D., Schellekens, J., Dankert, J., Peeters, M. Sensitivity of three urinary antigen tests associated with clinical severity in a large outbreak of Legionnaires' disease in The Netherlands. J Clin Microbiol; 40(9): 3232-3236, 2002.

[106] Uldum, S. A., Molbak, K. (2002). PCR as a routine method for diagnosis of Legionnaires' disease. In: Marre R et al., eds. Legionella, Washington DC, ASM Press, 213-215, 2002.
[107] Jonas, D., Rosenbaum, A., Weyrich, S., and Bhakdi, S. Enzyme-linked immunoassay for detection of PCR-amplified DNA of legionellae in bronchoalveolar fluid. Journal of Clinical Microbiology; 33(5):1247-1252, 1995.

[108] Murdoch, D. R., Jennings, L. C., Light, G. J, and Chambers, S. T. Detection of Legionella DNA in guinea pig peripheral leukocytes, urine and plasma by the polymerase chain reaction. Eur J Clin Microbiol Infect Dis; 18(6):445-447, 1999.

[109] Murdoch, D. R., Walford, E. J., Jennings, L. C., Light, G. J., Schousboe, M. I., Chereshsky, A.Y., Chambers, S.T., and Town, G. I. Use of the polymerase chain reaction to detect Legionella DNA in urine and serum samples from patients with pneumonia. Clin Infect Dis; 23(3):475-480, 1996.

[110] Steinert M, Hentschel U, Hacker J. Legionella pneumophila: an aquatic microbe goes astray. FEMS Microbiol; 26(2):149-62, 2002.

[111]Lin, Y. S., Stout, J. E., Yu, V. L., and Vidic, R. D. Disinfection of water distribution systems for Legionella. Semin Respir Infect; 13(2):147-159, 1998.

[112] Steinert, M., Ockert, G., Lück, C., and Hacker, J. Regrowth of Legionella Pneumophila on a Heat -disinfected plumbing system. Zentralbl Bakteriol; 288(3):331-42, 1998.

[113] Bissen, M. and Johann, J. Legionella in Drinking Water Distribution Systems. Technology and Services; 1-3, 2004.

[114] Wood, J. M. Evolutionary aspects of metals ion transport through cell membrane, in Sigel H (ed): Metal Ions in Biological System. New York, NY, Marcel Dekker; 223-237, 1984.

[115] Lin, Y. E., Vidic, R. D., Stout, J. E., and YU, V. L. Individual and combined effects of copper and silver ions on inactivation of Legionella pneumophila. Wat res; 30: 1905-1913, 1996.

[116] Liu, Z., Stout, J. E., Tedesco, L., Boldin, M., Hwang, C., Diven, W. F., Yu, V. L. Controlled evaluation of copper-silver ionization in eradicating Legionella pneumophila from a hospital water distribution system. J Infect Dis; 169(4):919-922, 1994.

[117] Muraca, P., Stout, J. E., and Yu, V. L. Comparative assessment of chlorine, heat, ozone, and UV light for killing Legionella pneumophila within a model plumbing system. Appl Environ Microbiol; 53(2):447-53, 1987.

[118] Muraca, P. W., Yu, V. L., and Goetz, A. Disinfection of water distribution systems for Legionella: a review of application procedures and methodologies. Infect Control Hosp Epidemiol; 11(2):79-88, 1990.

[119] Domingue, E. L., Tyndall, R. L., Mayberry, W. R., and Pancorbo, O. C. Effects of three oxidizing biocides on Legionella pneumophila serogroup 1. Appl Environ Microbiol; 54(3):741-747, 1988

[120] Fraser, D. W., Tsai, T. R., Orenstein, W., Parkin, W. E., Beecham, H. J., Sharrar, R. G., Harris, J., Mallison, G. F., Martin, S. M., McDade, J. E., Shepard, C. C., Brachman, P. S. Legionnaires' disease: description of an epidemic of pneumonia. N Engl J Med ; 297(22):1189-1197, 1977. 